\title{
Toward Standardizing Indigenous Liturgical Music Compositions in Catholic Diocese of Ikot Ekpene, Nigeria
}

\author{
Johnson Akpakpan \\ Department of Music, University of Uyo, Uyo, Nigeria \\ Email: johnsonakpakpan@yahoo.com
}

How to cite this paper: Akpakpan, J. (2018) Toward Standardizing Indigenous Liturgical Music Compositions in Catholic Diocese of Ikot Ekpene, Nigeria. Open Journal of Social Sciences, 6, 57-68. https://doi.org/10.4236/jss.2018.65005

Received: April 10, 2018

Accepted: May 13, 2018

Published: May 16, 2018

Copyright $\odot 2018$ by author and Scientific Research Publishing Inc. This work is licensed under the Creative Commons Attribution International License (CC BY 4.0).

http://creativecommons.org/licenses/by/4.0/

\section{cc) (i) Open Access}

\begin{abstract}
This paper sought to outline flaws inherent in indigenous liturgical music compositions in the Catholic Diocese of Ikot Ekpene. Recently, there has been a proliferation of indigenous liturgical Catholic songs for the various parts of the Mass by "untrained composers" in the Diocese. Due to the level of music training, the composers of most of these songs are always composed with no reference to both Western and African music theories. For this study, three indigenous compositions were collected, transcribed into staff notation and analysed. It was observed that all these compositions were in solfa-notation, a less accurate mode of notating music. The works under study had flaws ranging from notational, melodic, harmonic, metrical, modal and textual errors. However, if the choirmasters and organists who incidentally double as composers of most indigenous songs used in the Diocese are given basic training in music theory, the standard of their works would improve.
\end{abstract}

\section{Keywords}

Liturgy, Church Music, Standardization, Music Composition

\section{Introduction}

The Mass or celebration of the Eucharist, which is the principal liturgy of the Catholic Church, embodies Gloria, Sanctus, Agnus Die, Peter Noster and Kyrie set to music. There are also offertory and communion songs, as well as songs before and after the gospel. World outstanding composers like Mozart at one time or the other composed most parts and songs for the Mass.

Many writers have noted the inseparability of music and the Catholic Liturgy. One of such, Ratzinger [1] (Pope Benedict XVI, the Pope Emeritus) (1986) 
notes:

From the very beginning, liturgy and music have been quite closely related. Mere words do not suffice when man praises God. Discourse with God goes beyond the boundaries of human speech. Hence, by its very nature, the liturgy has everywhere called upon the help of music, of singing, and of the voices of creation in the sounds of instruments. The praise of God, after all, does not involve only man. To worship God means to join in that of which all creatures speak (p. 1).

Although the relationship between music and liturgy is made clearer by Ratzinger's writing, he adds that "their relationship has always been a difficult one as well, above all in times of cultural change and at turning points in history" and that "today, the question of the right form of music in worship is...disputed." If "the question of the right form of music in worship is...disputed" today, therefore, it can be adduced that certain gamut of music in the Catholic liturgy lacks the musical refinement and is not in line with the traditional liturgical precepts. According to Terry [2] (1907), "Sacred music should consequently possess, in the highest degree, the qualities proper to the liturgy, and precisely sanctity and goodness of form, from which its other character of universality spontaneously springs" (p. 12). Mike [3] further writes that: "musical judgment asks whether a given composition has the necessary aesthetic qualities that can bear the weight of the mysteries celebrated in the Liturgy. It asks the question: Is this composition technically, aesthetically, and expressively worthy?" (2012, para. 123). He adds that:

This judgment requires musical competence. Only artistically sound music will be effective and endure over time. To admit to the Liturgy the cheap, the trite, or the musical cliché often found in secular popular songs is to cheapen the Liturgy, to expose it to ridicule, and to invite failure. (para. 124)

The preceding shows that any liturgical music composition should have all degree of artistic refinement and is devoid of elements that attempt to portray it as being profane.

Initially, the Catholic Liturgy was mainly celebrated in Latin and sung as plainchant. After Vatican II and the introduction of inculturation, there was a choice for Catholic dioceses/parishes around the globe to celebrate and sing the liturgy in the languages of the places they were situated. According to Beall [4] (1996), by definition, inculturation is "the creative and dynamic relationship between the Christian message and a culture or cultures" (para. 2). The introduction of inculturation into the Catholic liturgy, which allows the Mass and other Catholic rites to be said in the local dialects of people, has given rise to a gamut of indigenous compositions that are used in the contemporary Catholic liturgy in many dioceses including Ikot Ekpene.

Pope John XXIII created Catholic Diocese of Ekpene in 1963 through the effort of late Bishop James Moynag of Old Calabar Diocese. However, Catholicism 
had existed in the present geographical area that makes the ecclesiastical jurisdiction of the Diocese. At the creation of the diocese, late Dominic Cardinal Ekandem was appointed its bishop, the post he held until his transfer to the newly created Catholic Diocese of Abuja in 1989 as its first bishop. His transfer necessitated the appointment of Bishop Camillus Etokudoh in 1989. Bishop Camillus Etokudoh served from 1989 to 2009. When the Vatican transferred him to the Catholic Diocese of Port Harcourt in 2009, Rt. Rev. Monsignor Sylvanus Etuk was appointed as the Diocesan Administrator. In 2010, Most Reverend, Camillus Umoh was appointed as the substantive Bishop of the Diocese

Music at the inception of Catholic diocese of Ikot Ekpene was often sung in Latin, thus the plainchant was most was employed in the liturgy. The indigenous language of the people (predominantly Annang) was rarely used in worship as Latin was employed in all forms of liturgical functions. Since Vatican's introduction/institutionalization of inculturation (the practice that allows certain aspects of the culture of the people in worship), there has been a proliferation of indigenous liturgical catholic songs used for the various parts of the mass. However, these are products of untrained composers whose songs were composed without recurs to both Western and African compositional principles. Ideally, a composer should have a guiding framework and should take cognisance of why and how he employs various elements of music in his compositions. If we go by the saying: "the best of composers are those that are indebted to the works of their forebears" or "composers do not copy, they steal", we can conveniently allude that these composers had some missing gaps.

Without a study of or reference to music theory in both African and Western parlances, we can confirm that these indigenous composers had some missing gaps. With these gaps, therefore, one wonders if the indigenous Catholic songs in the diocese are apt enough, consideration the musical background of their composers.

For this study, the researcher randomly collected and analysed fifteen songs without considering their composers. Out of these, three songs that had the characteristics fifteen were selected and presented in this discourse. They include Dibere Ye Nyin (Stay with Us), Koro Ima Esie Odude Ke Nsinsi (For His Love is Forever) and Akam Mbemiso Ebo Edisana Communion (Prayer before Communion).

The study looked at selected indigenous liturgical music compositions and their conformity to the conventional music theory principals. The study was aimed at elucidating the degree of conventionality or non-conventionality of these pieces to existing music theoretical rules.

\section{Analysis of the Selected Compositions}

The selected compositions though originally notated in solfa-notation were, however, transcribed without alteration into staff notation for the purpose of this study. This was done to facilitate easy analysis of the songs. The pieces were 
analysed for Notational/Metrical Errors, Harmonic correctness/Errors, phraseological and textual misapplications. These are presented below:

\subsection{Dibere Ye Nyin (See Appendix) by Emem Umorem}

\section{Notational/Metrical Errors}

1) Use of fermatas instead of extension bars at 7, 14, 17, 24, 31, 34, 37, 38, 41, 44,59 , and ambiguous fermatas at the last bar.

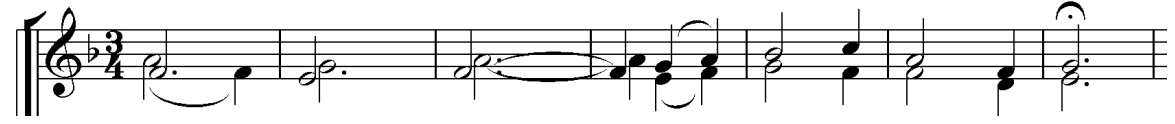

To balance, for instance, the opening phrase should have been written without the fermata thus:

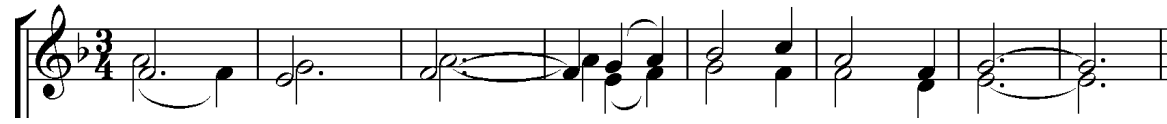

This should be applicable to all points where the formats are used in the piece.

2) The last bar with four crotchets does not also fit into the overall metrical frame of the piece and there is an explanation for this.

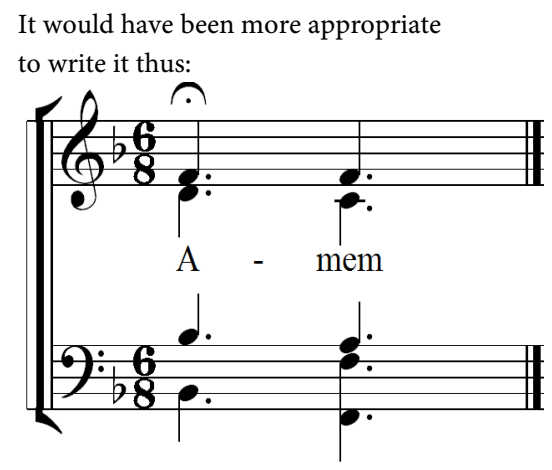

Instead of:

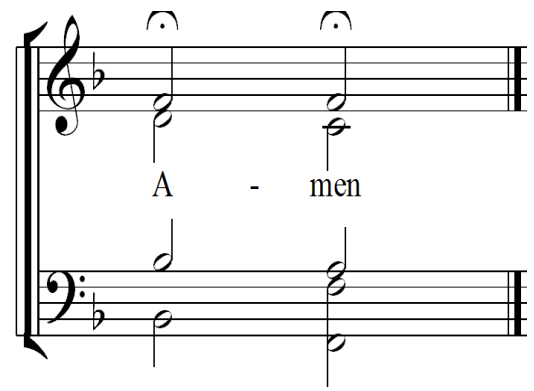

A close examination of the internal metrical shape of the piece is suggestive of $\mathbf{8}$ instead of $\begin{aligned} & \mathbf{3} \\ & \mathbf{4}\end{aligned}$ as stipulated by the composer. For instance, bar 25 to 31 would have better been written thus:

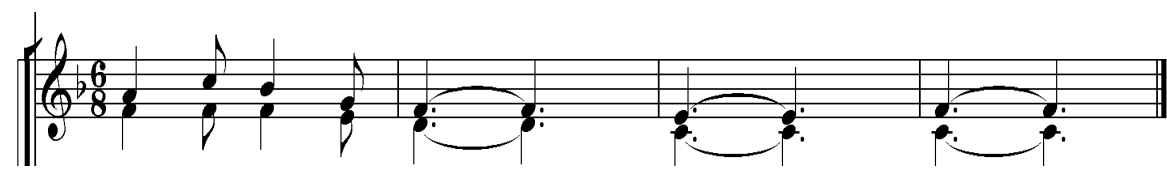

Rather than:

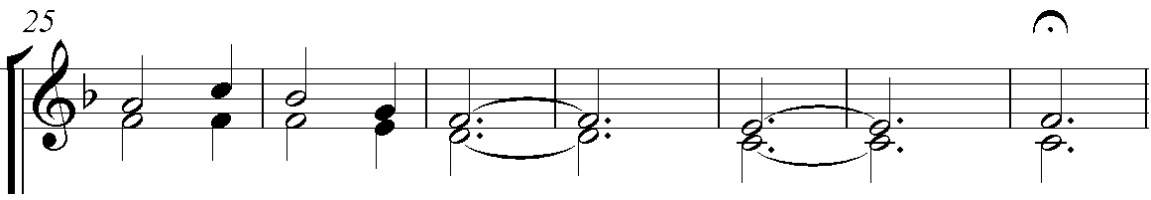

Notice the symmetrical balance in the former, assuming the phrase is be 
divided into two equal parts.

\section{Harmonic Errors}

\section{1) Part Crossing}

There is part crossing between the soprano and alto in the first four bar of the piece thus.

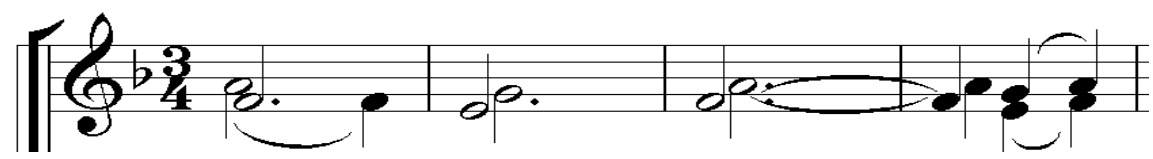

This can be very misleading to the ear and breaks one of the basic laws of part writing. This could have been better written with the notes of soprano interchanged with alto thus:

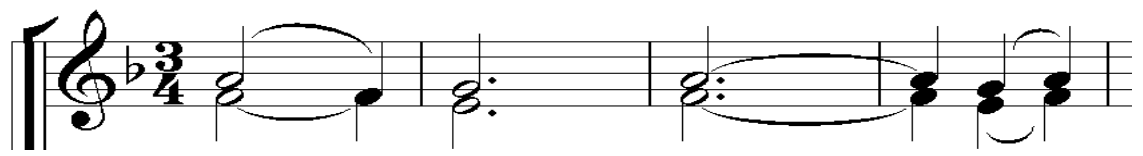

It is to be noted that this error could not have been noticed with only the tonic solfa as used by the composer, but with staff notation, the error is so glaring.

\section{2) Parallel Eighths and Consecutive/Hidden Fifths}

There is a total of ten Parallel eighths and fifths in the piece. These are professionally unacceptable because western harmonic principles are implied in the piece notwithstanding the text which is in vernacular. For instance, there is one (1) parallel eight and two consecutive fifths in bar twelve (12) alone. These are parallel eight between tenor and bass, and consecutive fifth between soprano and tenor and between soprano and bass as shown in the excerpt.

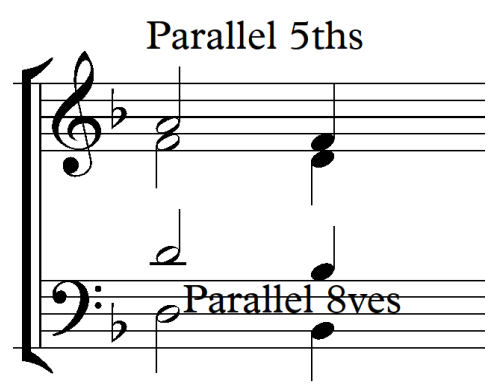

\section{3) Principles of Voice Leading}

In this piece, the composer has adhered to the basic principles of voice leading and chord progression.

\section{4) Textual Error}

The composer did not consider the tonal inflexion of the most words in the text in his melodic curves. For instance, using the same pitch for the Obong (Lord) likely will mislead the listener the word Obong (Mosquito). Obong (Lord) is usually pronounced "high-Low" while (Obong) (mosquito) is usually pronounced High-High. Let's take opening three bars in tenor as an example.

Opening three bars in tenor as an example. 


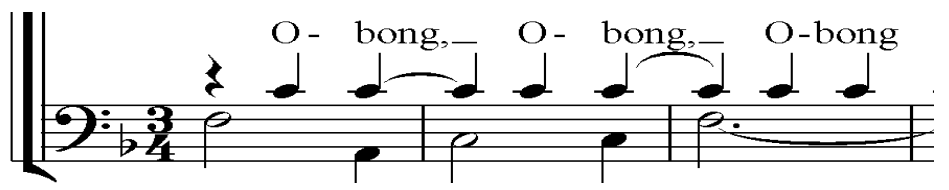

Without much distortion to the harmonic outline in the preceding, it would have been better to write to write the above thus:

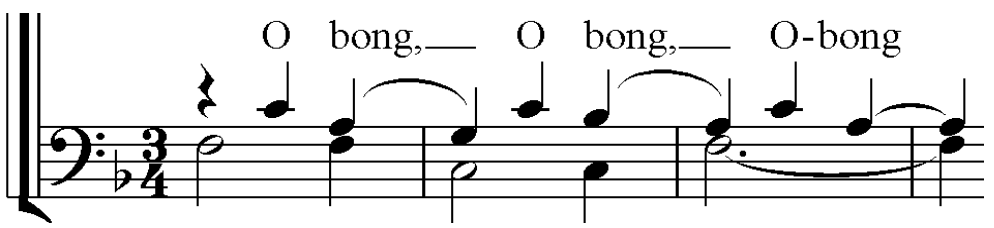

Textual errors are numerous in the piece but the overall harmonic layout employed was western with orientation. The research does not also suggest, however, that composers should always be rigid in adhering to the tonal inflexion of the words because this could also inhibit the musical creativity or may lead to musical redundancy of sections of the piece.

\subsection{Koro Ima Esie Odude Ke Nsinsi by Joe Oliver}

The use of rests at the opening bar of this is notation wrong. There is no indication of the purpose of the rest. Ideally, the piece that should have started with the last crotchet (two quavers) in the bar as an anacrusis. However, the composer out the lack of knowledge basic music theory started the bar with rests of three crotchets.

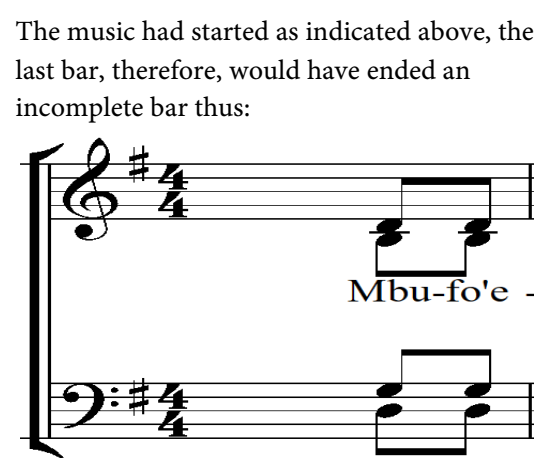

The music had started as indicated above, the last bar, therefore, would have ended an incomplete bar thus:

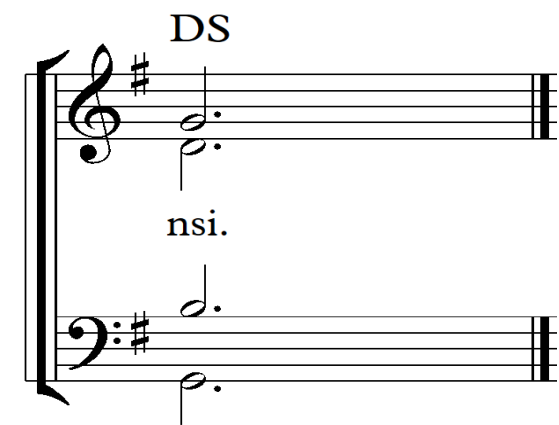

Instead of:

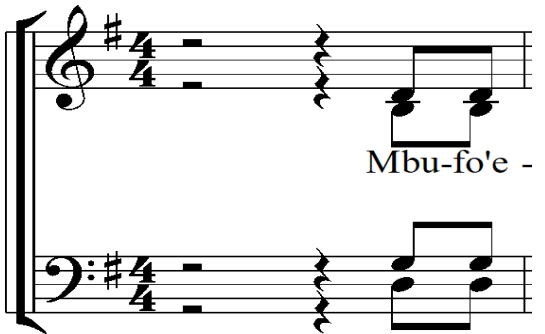

Instead of:

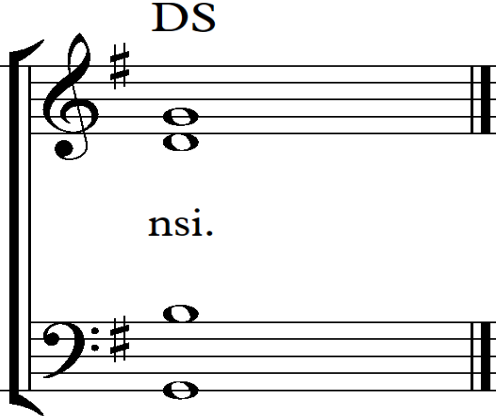




\section{Harmonic Error}

\section{Parallel Octaves and Consecutive/Hidden Fifths}

There are eight Parallel octaves and six hidden fifths in the piece. These are professionally unacceptable because western harmonic principles are implied in the piece notwithstanding the text, which is in vernacular. For instance, in bars, four (4) and five (5), four of such faults are noticed. These are two parallel Octaves between soprano and bass in bar four (4), consecutive fifth between tenor and bass in bar four (4) and hidden fifth between soprano and bar in bar five. These are shown below:

\section{Parallel 8ves} Parallel 8ves Hidden 5ths

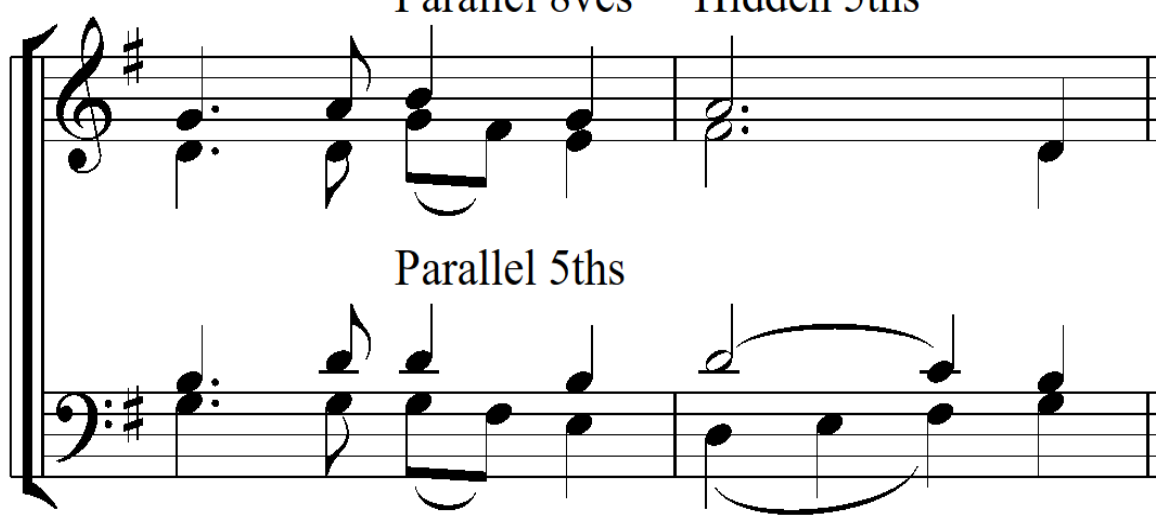

\section{1) Principles of Voice Leading}

In this piece, the composer adhered to the basic principles of voice leading and chord progression.

\section{2) Textual Misapplication}

The composer considered the tonal inflexion of the most words and reflected it them melodic curves without much distortion to the harmonic outline.

\subsection{Akam Mbemiso Ebo Edison Communion by Emem Umoren}

\section{Notational/Metrical Errors}

1) Use of fermatas instead of extension bars at 24.

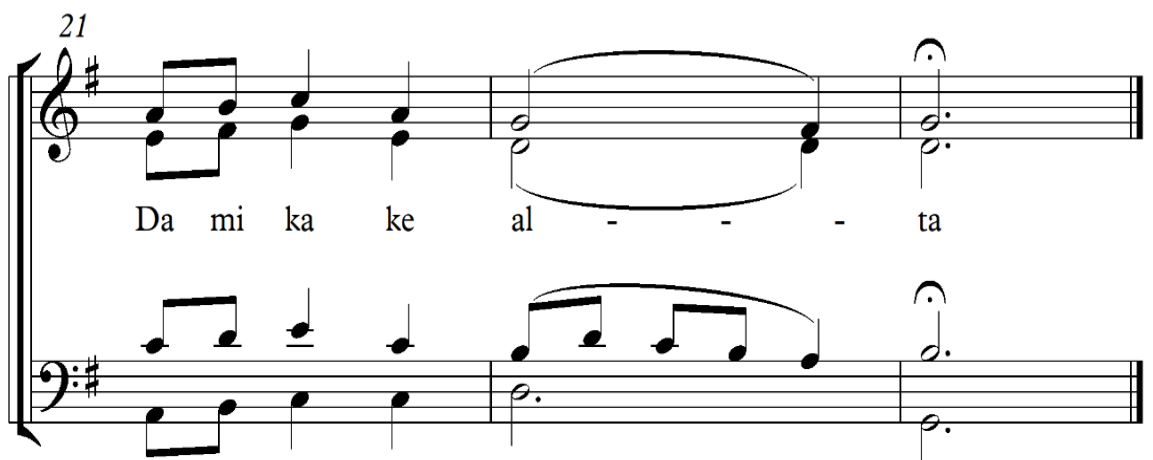

To balance, for instance, the last phrase should have been written without the fermata thus: 


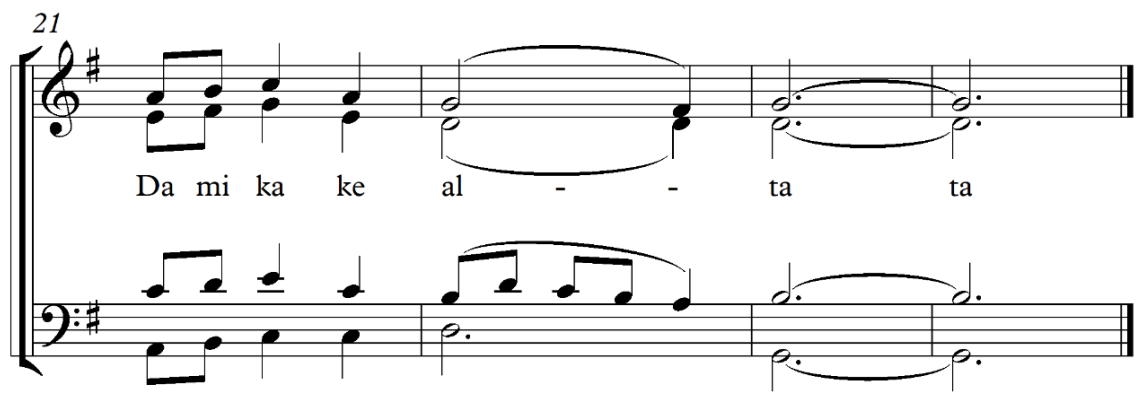

Thus the number of bars would be had been extended to twenty four (24).

2) The last bar with four crotchets do not also fit into the overall metrical frame of the piece and the composer of the song may give an adequate explanation for this.

\section{Harmonic Errors}

\section{1) Part Crossing}

There was no part crossing in this piece.

\section{2) Parallel Eighths and Consecutive/Hidden Fifths}

There is a total of seven (7) parallel octaves and two (7) consecutive fifths were found in the piece. These included two parallel octaves between soprano and bass in bar twenty (21), and consecutive fifth in bar two (2) which shown below:
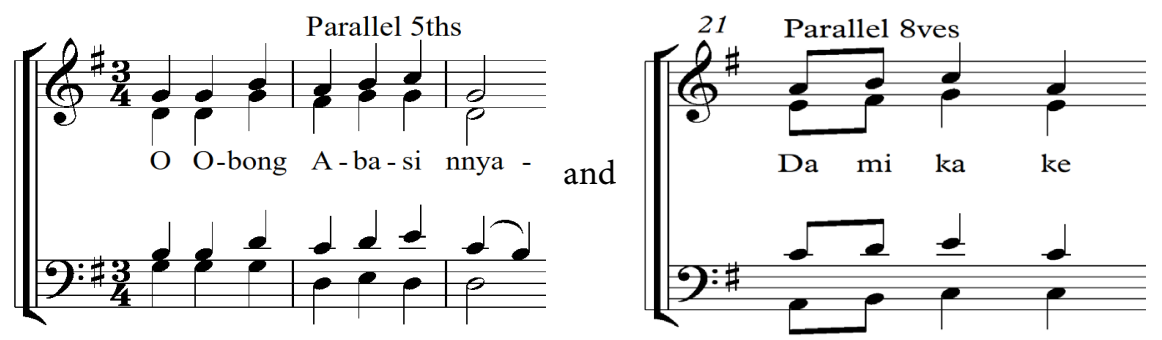

\section{3) Principles of Voice Leading}

The composer adhered to the basic principles of voice leading and chord progression in this piece.

\section{4) Textual Misapplication}

They are a close correlation between the melodic contours and the text.

\section{Findings}

It was observed that all indigenous composed songs used in the liturgy were written in solfa notation. The pieces under study indicated that their composers are naturally endowed musically despite the numerous flaws which characterized their pieces. Although the focus of this research was not on composers, however, it would not be out of place to note that there is a possibility to decipher the level of the musical training of composers by taking a look at their works. In this situation, it is evident that these works were written by composers with no formal music training. The number of faults found in the selected pieces can attest to this. The use fermatas as means of completion of phrases in some of the cited works indicated that their composers never had any musical drilling in melody 
writing or form and analysis. The use parallels octaves and consecutive fifth extensively also, is suggestive that the composers of these works had no formal training in basic harmony. It was observed in that the harmony in pieces were modelled after existing western hymns, therefore, if the composers of these works were trained formally, their harmonies would be consistent with harmonic principles as obtained in those models. Therefore, the inherent parallel octaves, hidden and consecutive fifths were not a deliberate attempt by the composers to depict African harmonic principles. The faults were, however, a depiction of the lack of understanding by these composers of the models they were trying to imitate.

For any liturgical music composition to be apt, it must be artistically beautiful. According to Mason [5] (p. 4), the melodic range and contour, the harmony, rhythm and tempo of any liturgical music must be aptly suited to singing by the intended music minister and must have enduring appeal. It is on this note that composers of liturgical songs must be appropriately trained for their works to have some degree of beauty. With respect to melodic consideration and its aptness and relation to the indigenous language of the composition, Akakpan [6] (2010, p. 54) discourses the "needs to consider the correlation between...melodic contour and tonal configuration of chosen text." However, in some of the selected works, the melodic contours were at variant with the natural inflexions of the text of the music.

\section{Conclusions}

Despite the shortcomings noticed in these compositions, their composers may be adjudged to be creative and their works have been used in worship in most parishes in the Diocese and even at the Diocese liturgical functions. The songs are widely accepted by both the choirs and congregations without considering their liturgical implications and appropriateness. However, if these composers are given basic training in music theory, form, and analysis, their musical horizon would be broadened and their composition would be professionally sound and most errors found in their pieces would be eliminated.

Therefore, it is the researcher's option that regular seminars and workshops are mounted for composers who sometimes function as choirmasters, to broaden their musical horizons. These, in turn, would reflect positively on the liturgical music compositions in the Diocese. Apart from this, it is necessary to set up a functional music directorate to censor the gamut of compositions and decipher their appropriateness or inappropriateness for liturgical functions in the Diocese.

\section{References}

[1] Ratzinger, J. (1986) Liturgy and Church Music. Sacred Music. https://media.musicasacra.com/publications/sacredmusic/pdf/liturgy\&music.pdf

[2] Terry, R. (1907) Catholic Church Music. Greening \& CO., LTD., London. 
[3] Mike, C. (2018) Church Music Philosophy and Guidelines (Roman Catholic). http://www.internetmonk.com/archive/church-music-philosophy-and-guidelines-r oman-catholic

[4] Beall, S. (1996) Translation and Inculturation in the Catholic Church. Adoremus. http://www.adoremus.org/1096-Beall.html

[5] Mason, P. (2012) Guidelines: Music Within the Mass. http://www.liturgydow.org.au/assets/guidelines-music_within_the_mass.pdf

[6] Akpakpan, J. (2010) The Nigerian Art Music Composer, His Training, Vocal Compositions and His Language. Journal of Association of Nigerian Musicologists, 4, 46-57. 
Appendix

DIBERE YE NYIN

EMEM UMOREN

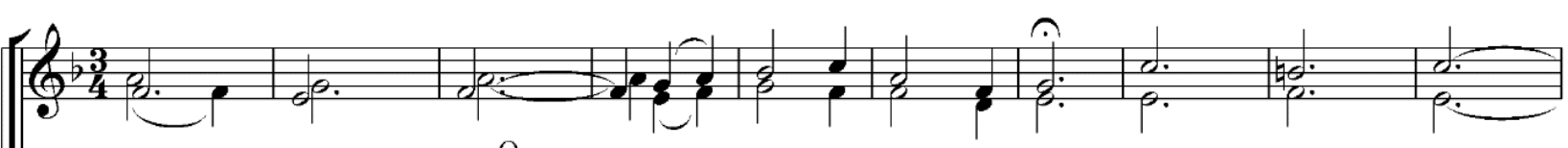

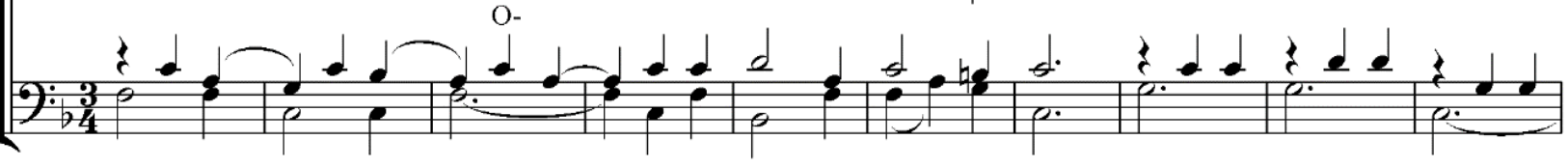

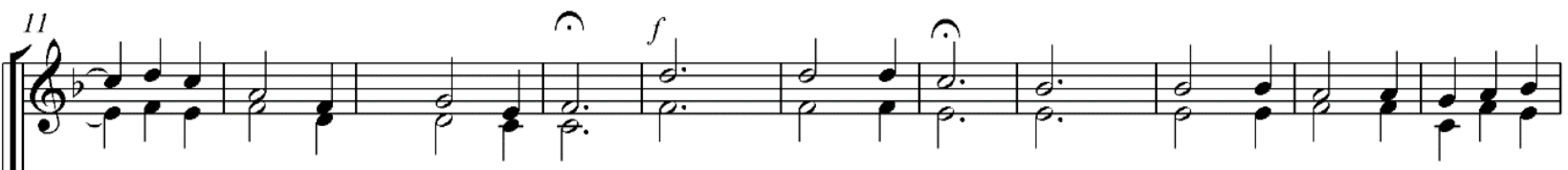

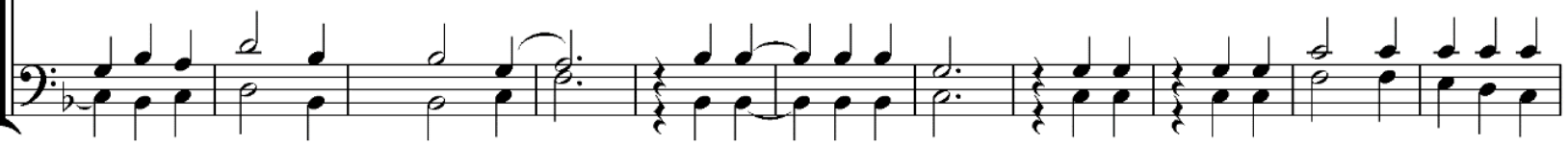

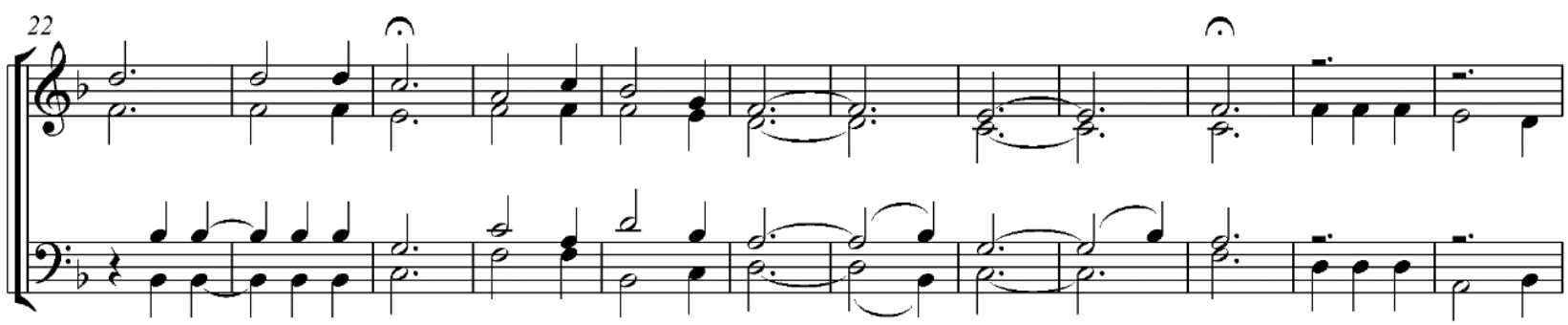

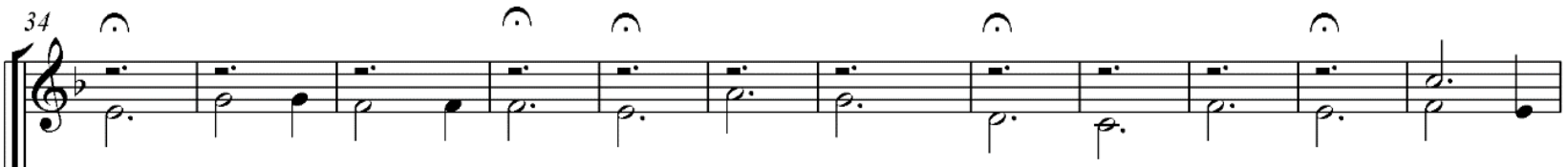

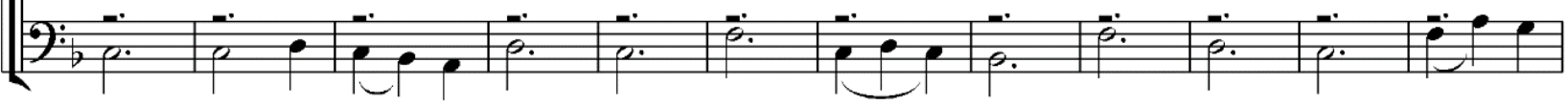

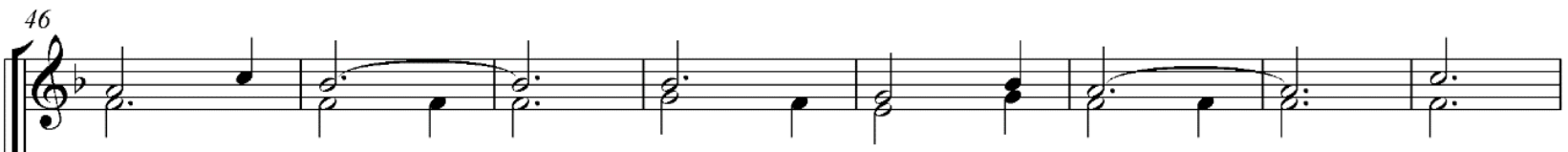

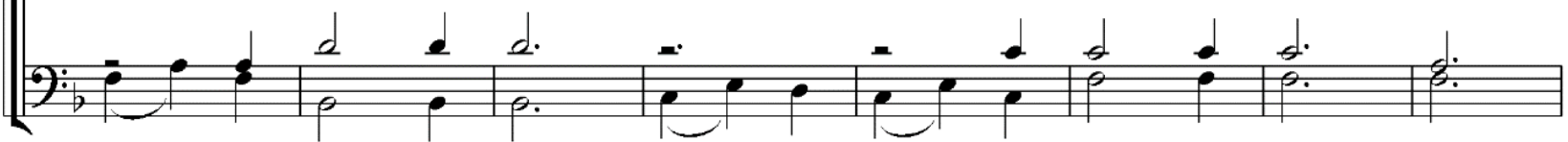

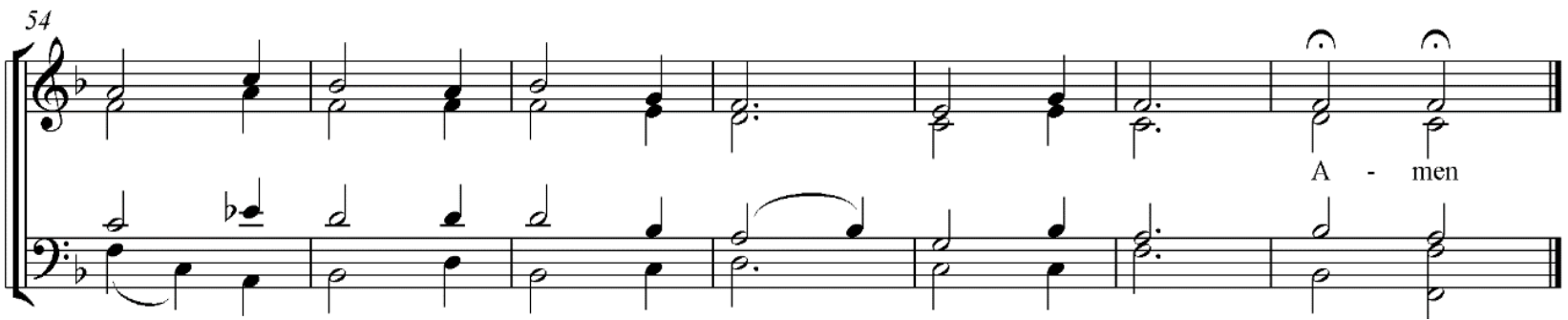


AKAM MBEMISO EBO EDISANA COMMUNION

EMEM UMOREN
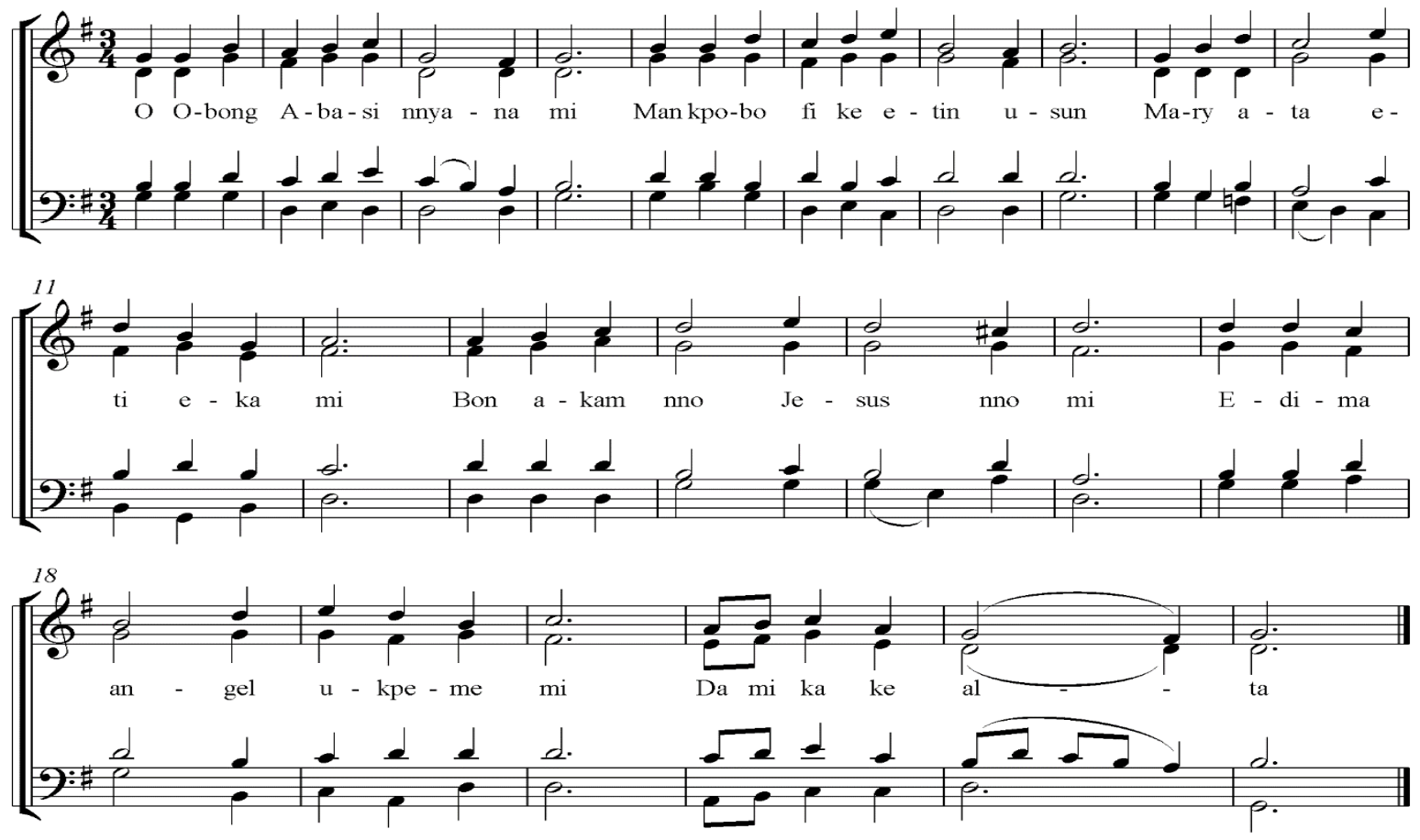

KORO IMA ESIE ODUDE KE NSINSI

JOE OLIVER
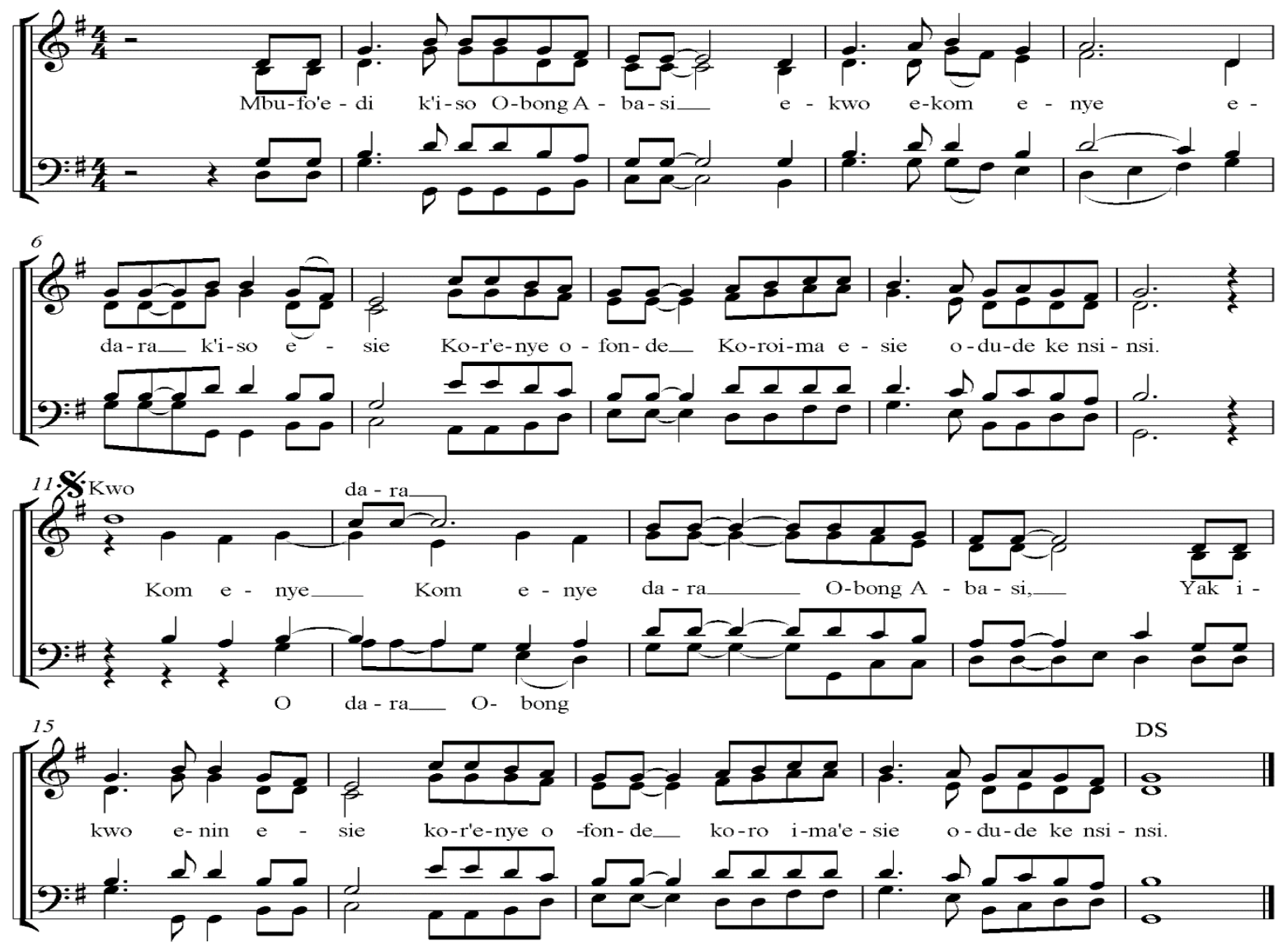